\title{
COMPLEMENTARY STYLISTIC RESONANCE IN JAPANESE PLAY FRAMING
}

\author{
Hiroko Takanashi
}

\begin{abstract}
Building on the theoretical frameworks of frame and stance, this paper aims to demonstrate how play framing is manipulated in culturally meaningful contexts of Japanese conversations among friends and to show the consequences it brings to social life. This study particularly focuses on speech style shifts across speakers as one of the linguistic play-framing devices. The notion of "complementary stylistic resonance" as a special kind of pragmatic resonance is introduced to investigate how speech participants meta-linguistically signal their common stance of constructing a play frame. It was observed that in play they characteristically use the speech style of each imagined persona in a complementary social relationship such as "teacher and student," "husband and wife," and "American male and female in the dubbing register." The ideologies of those dichotomized social roles are spontaneously evoked between the speakers through meta-language practice, resulting in solidifying their ideologies. Furthermore, in play, speech styles of those social roles are exaggerated and maximally contrasted within the pairs so that their identities are easily recognized by the speech partners to successfully co-construct the play at hand and to enhance its humorous effects. Although there may be a gap between ideology and reality, complementary stylistic resonance in play helps speech participants reconstruct their language ideologies of socially salient roles in local language practice, which serves as the concrete and dynamic ground for the process of recreating a larger cognitive and interactive dimension of culture.
\end{abstract}

Keywords: Complementary stylistic resonance; Play; Frame; Stance; Style; Language ideologies.

\section{Introduction}

This study will reconsider the notion of framing and explore the dynamic role of framing situated in social life. Particular attention is paid to the way speech participants collaboratively construct a play frame by using highly pragmatic skills that further require socio-cultural knowledge. As a framing device, we examine speech style shifts that accompany the role playing in a play frame. Style shifts occur as the speakers enter a play frame to perform an imagined persona, which is interactionally maintained among the speakers. However, the imagined personae, and accordingly 
their speech styles, are different from one another, although they show pragmatic systematicity by being complementary to each other. In the kind of play frame treated in this study, when a speaker effectively portrays a persona through its characteristic speech style, another speaker performs another persona who stands in a complementary social position to the first through the use of its distinctive speech style. We will call this distinctive but systematically relational, pragmatic style shifting maintained across the speech participants complementary stylistic resonance.

Framing can be defined as a contextual orientation toward what is going on in a given context. It was first investigated by Bateson (1972) in anthropology, and then in other related fields such as sociology (Goffman 1974, 1981), interactional sociolinguistics (Gumperz 1982), and linguistics (Tannen 1993). These studies, despite the different focus of each field, coincide in that framing plays a fundamental role in social interaction because framing is both a system and process whereby speech participants perceive and perform what they are doing. Although these previous studies have set forth sound theories of framing, close investigation of how it is actually performed in situated discourse, as well as what consequences it brings to the bigger context of social life, is still lacking. This is particularly true for speech communities in which the target languages are other than English. By examining naturally occurring Japanese conversations, this study aims to demonstrate that the act of framing at the discourse level relies on symbolic resources taken from the larger socio-cultural context, while simultaneously reshaping that socio-cultural context.

\section{Literature review}

\subsection{Stancetaking}

To bridge the linguistic and socio-cultural style, this study will build on the theoretical framework of stancetaking. The recent theory of stance (Du Bois 2002a,b, 2003, 2007; Englebretson 2007; Hunston and Thompson 2000) proves that framing is not merely a subjective but also an intersubjective act, and that it provides social actors with the ground on which they can negotiate each other's relative standpoint in its process. Du Bois $(2002 a, b, 2003$, 2007) illustrates that stancetaking entails three simultaneous sub-acts: evaluating, positioning, and aligning. In speech interaction, subjects (speech participants) evaluate the stance object, decide on their position relative to the stance object, and align their positions in relation to other subject(s) co-participating in the speech activity. Taking a stance requires aligning (i.e., an intersubjective act), in addition to evaluating and positioning (i.e., subjective acts). Thus, aligning is a vital element of stancetaking, magnifying the intersubjective and dialogic nature of stancetaking between individuals in social interaction. Intersubjectivity thus completed 
by alignment is an essential factor not only for stancetaking but also for framing, because framing necessarily involves intersubjectivity for speech participants to know that they are performing a single activity based on common understanding. This phenomenon of framing can be regarded equivalent to what Gumperz $(1982,1989 \mathrm{a}, \mathrm{b})$ calls "contextualization cues," and together with stancetaking it should be seen as a dynamic process constantly being manipulated among speech participants.

In search for the ways in which framing and stancetaking are manipulated in ongoing speech, this study focuses on linguistic style-shifting seen across the speech participants as well as its background language ideology. Linguistic style-shifting in play seems to require of speech participants two kinds of ability: (1) the pragmatic ability to recognize that the style shift marks the frame shift, and (2) the pragmatic and socio-cultural ability for the co-participant to identify what type of social character is being portrayed and to respond also playfully, and moreover, appropriately, enacting the complementary social character in that cultural context. Thus, speech participants take a stance relative to both framing (i.e., shifting to a play) and the social characters being performed in the play.

\subsection{Speech style}

\subsubsection{Style}

Style comes in various manifestations such as clothing, make-up, hair style, physical representations such as gestures and body type, favorite music, vehicles, a range of personal belongings, a higher level of style that has to do with the person's philosophy about life as indicated by the word "life style" (e.g., eating habits, as in vegetarian), or any other choice a person deliberately or just spontaneously makes and pursues in his or her life based on certain beliefs or preferences, either temporarily or over a long period of time (Eckert and Rickford 2001). Tannen (1984: 14) views speech as "one element of a range of behavioral characteristics that make up personal style." Linguistic style, or speech style, may have a close link with other channels of representation of style (e.g., Mendoza-Denton (1997) demonstrates such a link in her study of adolescent Latinas in the Bay Area of Northern California), constituting as a whole social characteristics of the individual and the social category with which the individual is associated. In sociolinguistics, however, the primary attention for style has been paid to the linguistic aspect, which this study follows. 


\subsubsection{Systematicity of speech style}

The notion of speech style is central to sociolinguistics that is deeply concerned with the relation between sociolinguistic variation and its indexical social meaning. Speech style can be defined as the systematic organization of language form for social effects, where language use indexes the speaker's various types of social identity (Agha 2007; Eckert and Rickford 2001). Three significant aspects of speech style - "systematicity," "indexicality," and "process" - will be discussed. These three aspects should not be regarded in isolation, but rather as being intertwined with one another.

First, speech style does not merely refer to each occurrence of a linguistic phenomenon, or to a random assembly of some linguistic tokens, but also constructs a coherent system operated according to principles. Thus, different linguistic features can be grouped together under a single speech style if the same principle works for them. As Ervin-Tripp (1972) discusses, within a certain stylistic system, some stylistic forms often co-occur in a single utterance, where they stand in syntagmatic relations. Furthermore, on the discourse level, stylistic forms can be altered or substituted by other forms under the same system, in which case those forms across utterances hold paradigmatic relations to each other. Seen from a creative and dynamic perspective, systematicity that unifies such distinct linguistic forms under the same style is also at the heart of stylistic productivity and replicability.

\subsubsection{Indexicality of speech style}

Second, speech style operates through the mechanism of indexicality, which bridges the linguistic to social phenomena. In order for a given speech style to index a certain social meaning, both the speech style and its social meaning ought to be distinctive from, and identifiable among, other speech styles and corresponding social meanings. Style is described as "a social semiosis of distinctiveness" by Irvine (2001: 23) and "the maintenance of expressive identifiability" by Goffman (1974: 288), respectively. By virtue of indexicality, "distinctiveness" or "identifiability" on the linguistic level has the direct connection to its corresponding social phenomenon, namely the individual who uses the speech style and his or her characteristics such as personality and social identity. Moreover, the range of social meaning thus indexed by speech style extends from the individual level to the level of social groups or categories. That is to say, as Sapir (1958) points out, even though speech style is a way of distinctive self-representation of an individual's personality and social identity, it is also a characteristic display of a social category of which the individual is a member. Speech style is, after all, a social construct that categorizes social order. 


\subsubsection{Process of speech style}

Third, process is another essential characteristic of speech style. Mendoza-Denton (2001) succinctly describes this point: "linguistic style is defined not as still product but as relentless epiphenomenal process, a context-sensitive interaction between speakers' balance of innovative and conventional elements in their repertoire and hearers' expectations, together with the resultant attributions and interpretations that may or may not be intended by or known to the speaker" (p. 235). Since Labov's (1966) study of language variation in New York City, early studies on style in sociolinguistics were mainly concerned with revealing rather a fixed system of correspondence between stylistic varieties and social factors such as socioeconomic class, ethnicity, age, and gender, in the respective target language community. Recent sociolinguistic studies (Bucholtz 1996; Eckert 2000), however, view style as an open system, with an emphasis on the process through which speech style is constructed (Rickford and Eckert 2001).

We would like to discuss two issues at the core of speech style as process ideology and interaction. It is commonplace in linguistic anthropology to construe ideology as a system of belief, evaluation, attitudes, or one's understanding or conceptions of social values. Along this line, language ideology serves as the basis for the indexical relation between linguistic form and social meaning (Silverstein 1979, 1992; Schieffelin, Woolard, and Kroskrity 1998). In other words, speech style (language use) is mediated by ideology to have the indexical relation to social meaning. Irvine (2001) argues that "styles in speaking involve the ways speakers, as agents in social (and sociolinguistic) space, negotiate their positions and goals within a system of distinctions and possibilities. Their acts of speaking are ideologically mediated, since those acts necessarily involve the speaker's understandings of salient social groups, activities, and practices, including forms of talk" (p. 23-4). Employing cultural resources intervened by ideology, and therefore with the cognition of social values for those resources, speakers use and hearers interpret speech styles according to the attached social meaning, which they perceive to be characteristic to the speech style. Moreover, through the mediation of ideology, performance of such speech style results in re-signification of the very cultural resources used in that way (whether the old meaning of those resources is maintained or modified). This way, the three elements of cultural resources, ideology, and speech style altogether form a circle of the system of language and culture, where language use as performance is the locus of revitalizing

social meaning of cultural resources mediated by ideology. It is in this dynamic process that culture, including speech style and its language ideology, keeps evolving.

Interaction is another salient aspect of speech style as process because interaction between speech participants is a linear sequence that is observable and can 
provide evidence of how speech style is processed in the course of exchange of speech production and its response. Taking a close look at speech style in interaction will direct us to the understanding of how speech style is manipulated in the situated context between speaker and hearer, and, furthermore, how speech style is also a product of speech activity embedded in the context of communication. Proper understanding of a speech style is possible when the hearer properly infers situated meaning of the speaker's utterance. Gumperz (1996) argues that "situated understanding is to a large extent a matter of context-bound indirect inferences" (p. 374), and that such conversational inferences are highly culture-specific (Gumperz 1982, 1989a, b, 1996). This "cultural relativity" of conversational inferences suggests that they are based on socio-cultural values such as socially distributed knowledge and ideology, which are rooted deep in the cultural context. In the case of speech style, then, such conversational inferences involve socio-cultural understanding of the values of the speech style, such as ideologies about the social groups that use the speech style. After all, speech style is largely a social matter of positioning and representing the self in relation to others in the society to make it (the self) distinctive. Since this is a social phenomenon, speech style is subject to assessment by the hearer. Analysis of how speech style is used in the local interactional context can reveal the process by which the practice and resultant evaluation of speech style and its social values are dynamically manipulated.

\section{Purpose of the present study}

Building on the theoretical frameworks of frame, stance, and speech style, this paper aims to provide a close linguistic study of play in culturally meaningful contexts. Play is a form of interaction that encompasses a wide range of conversational humor, such as joking, teasing, mocking, bantering, being non-serious, acting, and so forth. The commonality among these activities is that an imaginary or hypothetical world is overlapping the real world to some extent. Play is defined as fulfilling the following three conditions: entailing irrealis modality, having semantic/pragmatic incongruity, and being performed with pleasure by the speech participants (Takanashi 2004). While play has long been of interest in the scholarship of linguistic anthropology as a performance fundamental to humans (e.g., Bateson 1972; Bauman 1977; Sherzer 1990), its interactional aspects and sequential process, particularly in non-English-speaking cultural contexts, still remain largely unexplored. In this paper, particular focus will be placed on speech style shifts performed and maintained across the speakers for the sake of play, analyzing naturally occurring Japanese conversations among friends.

Speech style in normal contexts is attributed to the representation of the speaker's identity, and so speech style shifts are the speaker's strategies to manipulate 
self-representation as well as to show subtle attitudes toward the addressee, referent, topic, and so forth. Unlike such normal cases in non-play contexts, speech style employed in play contexts enacts an imagined persona. This holds true even in the case in which the enacted persona is supposed to be the speech participant or any other existing person; it is still imagined because the play context is not real, although it cannot entirely elude the voice of the speaker (Bakhtin 1981) because of his or her role as "animator" and "author" from the perspective of Goffman's (1981) participation framework. Given that peculiarity, speech style shifts characteristically occur as the context shifts from non-play to play, which indexes the initiation of the play frame as the voice shifts from the speaker's to an imagined persona's. Accordingly, the working of ideology here is somewhat different from non-play contexts due to the fact that the enacted persona is imagined - that person is rather a generalized member of the extremely "ideologized" image or stereotype of a social category. Ideology is ultimately nothing tangible but rather a cognitive entity that people bear in mind. This nature of ideology seems to be magnified in play contexts and can serve as a rich locus of investigation of socially distributed and generalized ideology of certain social groups.

Finally, particularly treating the case in which the hearer actively participates in play initiated by the speaker, the present study examines how exactly such playful stances are linguistically shown in speech style shifts between the speech participants to collaboratively construct a play frame. We will use "resonance" as the analytical tool to show the linguistic evidence of interactional speech style shifts as a framing device. Resonance is a notion proposed by Du Bois (1999), who defines it as "the activation of intrinsic potential affinity in dialogic language use" and "a property of relations between elements in discourse," which, "as such cannot be attributed to any element in isolation" (p. 2). Emphasizing the dialogic nature of resonance, Du Bois further notes that it is a process of "linguistic (grammatical, lexical, phonological, semantic) feature-matching." This paper wishes to add a new type of resonance, namely "pragmatic resonance," for the linguistic elements that are connected by pragmatic affinities, including socio-cultural relations. Under this type of pragmatic resonance falls "stylistic resonance," a special kind of pragmatic resonance that particularly builds upon pragmatic and socio-cultural values associated with speech styles. In an attempt to demonstrate the Japanese linguistic and cultural resources of framing, this paper analyzes resonance of speech style shifts across speech participants, who are enacting distinct personae occupying "complementary" positions in society.

Such "complementary" social positions are ideologized cognitive models, which are grounded on, but do not necessarily reflect, real social life. Ideologized, complementary roles are simplified, and therefore they are relatively clear-cut binary oppositions to each other within a socially salient category, such as "teacher" and "student" in the category of the educational institution. It should be noted that those 
social roles in a complementary pair become meaningful in a relationship - i.e., to use the above example, the "teacher" role is meaningful only in relation to the "student" role. This relational nature of complementation is in accordance with Bucholtz and Hall's (2005) "relationality principle," which stresses the relationality of identity. The social roles enacted in play in the current study evoke those roles' social identities, not only relational, but complementary, which also shows linguistically in the form of resonating distinct speech styles, each of which corresponds to its social role. Such complementary stylistic resonance is a type of play stance index in the collaborative practice of stancetaking for play framing.

\section{Data and methodology}

The data are drawn from audio-taped, naturally occurring casual conversations among Japanese friends. Three examples are extracted from three distinct conversations "STUDENTS" (45 minutes and 44 seconds), "GIRLFRIENDS-1" (79 minutes and 41 seconds), and "DRINKS-1" (48 minutes and 14 seconds), respectively - for qualitative analysis of playful interaction. All the conversations were audio-recorded in Tokyo in 2001, either at public facilities such as a coffee shop and a restaurant, or at one of the participants' houses. The number of speech participants ranges from two to five: two males in "STUDENTS," three females in "GIRLFRIENDS-1," and three males and two females in "DRINKS-1." The participants are all in their mid-twenties to early thirties. The transcription of the extracted play sequences followed the revised version of Discourse Transcription conventions (Du Bois 2006) developed from its original version (Du Bois et al. 1993), with one intonation unit of the Japanese text per line, provided with gloss and free translation underneath in separate lines. The transcription symbols and the abbreviations of the gloss are listed in Appendixes A and B, respectively.

\section{Analysis}

This section illustrates the analysis of complementary stylistic resonance across the speech participants to frame the current context as play. Each of the three examples shows different pairs of socially salient complementary roles performed in the imagined scenario of play: professor and student in Example 1, husband and wife in Example 2, and male and female in Example 3. 


\subsection{Example 1: Professor and student}

Example 1 is a same-sex conversation between two male friends in their mid-twenties. The conversationalists, $\mathrm{B}$ and $\mathrm{O}$, are casually talking, sitting at a table in a coffee shop. $\mathrm{B}$ knows that $\mathrm{O}$ wants to go to graduate school in the United States, and the main topic in the following passage is O's preparation for the application to graduate school.

(1)

$(($ STUDENTS) $)$

$<\mathrm{T}=00: 32: 35.00>$

$1 \quad$ B; (1.5) Dasu dake dashite-mire-ba?.

submit only submit-try-COND

'Why don't you just try submitting (the application)?'

$2 \mathrm{O} ; \quad$.. un,

yeah

'Yeah,'

3

... ichiou:,

for.the.time.being

4

.. dasu tame 'no, submit for LK

5

... mono wa tsukutte, thing TOP make

'Yeah, for the time being, I prepared the things to submit, and,'

6

$\mathrm{B}$ yeah

'Yeah,'

7

$\mathrm{O}$; .. ima sensei ni mite-moratte-nda [kedo:]. now teacher by see-BEN-COP but 'now I'm having it looked at by my professor.'

$8 \quad \mathrm{~B}$

[aa],

well

9 jaa,

then

10

ii jan,

fine FP

11 ..sore de: that as

12

.. un.

yeah

'Well, then it's fine like that, yeah.' 
$13 \mathrm{O} ; \quad \ldots @$

14@..@@Konshuu@no@getsuyoobi@ni@ this.week of Monday on

'This Monday,'

$$
(\mathrm{H})<(-)>\text { 'sensei ni 'denwasuru i-hazudatta no }</ \odot>\text {, }
$$
teacher to call be.supposed.to:PST NOMLIZER

@wasureteta@@ forget:PST

'I was supposed to call my professor on Monday, but I forgot it.'

$\mathrm{B}$;

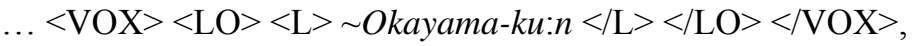

'Mr. Okayama,'

\section{Okayama-Mr.}

$18 \quad \mathrm{O} ; \quad(\mathrm{SNIFF})$

19

B;

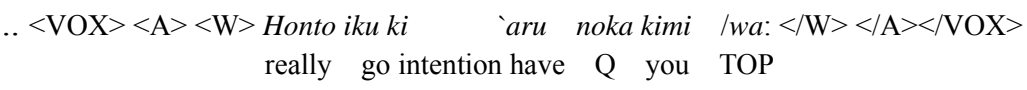

'Do you really intend to go?'

$\mathrm{O}$;
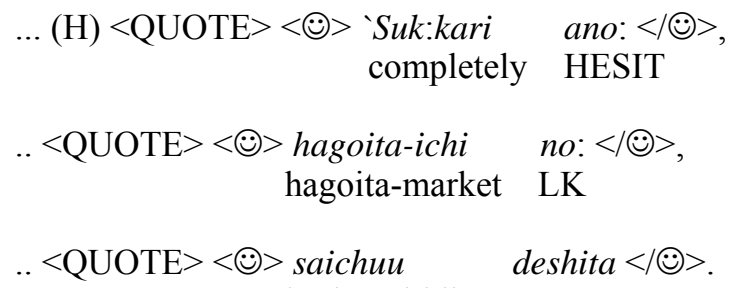
in.the.middle COP:PST

'I was completely in the middle of (working at) the hagoita market.'

$\mathrm{B} ; \quad . . \quad<\mathrm{HI}><\mathrm{W}>$ 'Sonna koto yatteru baai-ja `nai njanai `no: $</ \mathrm{W}></ \mathrm{HI}>$ ?. such thing do situation-NEG FP FP

'You're not supposed to be doing such a thing, are you?'

24 o; @@@

$25 \quad \ldots(\mathrm{H}) a$, ah

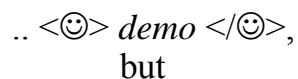

$<$;) $>$ nanimo: $</(;)>$, nothing

'But now (there's) nothing (I can do),' 
29

30 ...nee,

FP

... matsu dake dakara.

wait only because

'Because I only have to wait.'

They are talking quite seriously in the non-play context from line 1 to 12 . In line 1, sensing O's lack of confidence in being accepted to graduate school, B encourages $\mathrm{O}$ to try applying anyway. $\mathrm{O}$ responds in line 2 to 7 (intervened by B's backchannel in line 6) that he has already prepared the application materials and that they are currently being looked at by his advisor, to which B expresses his accord in line 8 to 12 . The serious mood maintained up to this point slightly changes in line 13 to 16 , as $\mathrm{O}$ confesses his irresponsible deeds in having failed to call his advisor regarding his application materials, in a self-mocking manner with laughter, laughing voice quality, and smiling voice quality. This shift of mood hints at the upcoming framing. This passage itself, however, is not play because its modality is not irrealis even though the speaker takes a playful stance to laugh at himself.

There is a sudden shift of modality from realis to irrealis in line 17, as B spontaneously starts playing O's advisor's role in his imagination of how he would react to O's irresponsible deeds, which $\mathrm{O}$ has just confessed in the preceding passage. This is considered as play because of its imagined situation, although it elaborates upon O's reported behavior. B's playful stance is signaled by his speech style shift. The most explicit style shift is observed in the address term Okayama-kun ('Mr. Okayama') that B uses toward O. The full last name followed by kun ('Mr./Mrs./Ms.') is a formal address term that contrasts with the casual one, usually a nickname, which is the form usually used by these friends; B normally calls $\mathrm{O}$ by his nickname Oka-chan (the shortened form of his last name followed by chan, the casual and affectionate version of kun), even though it does not appear in this excerpt. The speech style shift also appears in the prosodic features that co-occur with this formal address term used by a professor to his student; it is uttered in the recognizable change of voice quality with lowered pitch level in slower speed.

B continues playing the professor's role in line 19 as he maintains the same speech style while saying Honto iku ki aru noka kimi wa ('Do you really intend to go?'). Here, the second person pronoun kimi ('you') substitutes the previously used Okayama-kun ('Mr. Okayama') as the address term. This second person pronoun is rather distant and authoritative (also gendered because men generally use it), it is normally used by the superior to the inferior in the vertical social hierarchy, and, together with Okayama-kun ('Mr. Okayama'), it constitutes the formal and authoritative speech style of an older male professor talking to his student. Also in line 19 the verb ending noka used as a question particle that occurs before the post-positioned kimi wa ('you' plus topic particle) is a formal and authoritative speech 
style, resonating other linguistic tokens that invoke a professor's figure. The prosodic feature of the other's voice quality is used again in line 19, accompanied by other prosodic features of widened pitch level and rapid speech. These prosodic features, followed by the lengthening and rising tone at the end of the intonation unit adds to dramatization of an agitated professor who is offended by O's irresponsibility. These exaggerated linguistic and prosodic features altogether organize a systematic speech style of a professor when telling off his student, based on the speaker's ideology of a typical professor (e.g., older, male, and with dignity), but perhaps exaggerated.

Using conversational inferences and stereotypical images of professors, $\mathrm{O}$ recognizes the contextual framing of play in which an imagined situation is enacted with an imagined professor who may be represented differently from O's actual professor (and it is quite possible that B does not know O's professor in person). Staying in the same play frame and knowing that the voice in B's utterances in lines 17 and 19 is not B's own but the enacted professor's (even though B's own voice may be overlapped on it), $\mathrm{O}$ positions himself at the opposite to $\mathrm{B}$ in the paired social relationship of student and professor. That is to say, $\mathrm{O}$ plays the complementary role of a student (which may overlap himself in reality) to the role of a professor. This stancetaking, parallel to B's stance in terms of framing but complementary in terms of social roles, manifests itself in his complementary speech style shift from casual to formal and polite in line 20 to 22, as he says Sukkari ano, hagoita-ichi no, saichuu deshita ('I was completely in the middle of (working at) the hagoita market'). O's language use in these lines demonstrates complementary stylistic resonance to the professor's language use previously uttered by B. The hesitation word ano with lengthening in line 20 and the verb ending deshita (the past tense form of the polite version of copula desu as opposed to the plain version $d a$ ) help convey a figure of a polite student who reluctantly gives an excuse for his fault. Throughout these lines of 20-22, O employs the quoting voice quality as well as smiling voice quality that reveals his playful stance. Although smiling voice quality does not contribute to effective characterization of the student's role, it certainly indexes O's playful stance just as other stylistic resources of a student do. The role play ends in line 22, and in line 23, B shifts back to his normal speech style as the final particle no (also functions as a question particle in this context) at the end of the intonation unit indicates the casual speech, not a professor's. If B were still playing the professor's role, it would be the authoritative question particle noka. In addition, the higher pitch level indicates that it is not the professor's speech anymore: the lowered pitch level was used to characterize the professor in line 17. Recognizing that B is not playing anymore, $\mathrm{O}$ stops playing as well. After laughing, he continues his serious talk about the application process, which was temporarily intervened by their spontaneous play. 


\subsection{Example 2: Husband and wife}

Example 2 is a same-sex conversation between three female friends in their early thirties, K, S, and N. K invited $\mathrm{S}$ and $\mathrm{N}$ to her house in Tokyo for an informal dinner, where the conversation took place. The topic of the excerpted passage is the American way of calling a husband/boyfriend. The speech participants' play on address terms along with their metalinguistic assessments of it offers rich resources to understand Japanese language ideology of gender, and, more specifically, the relationship between men and women, whether they are married or not. Stereotypically, Japanese couples do not express affection as much as Westerners do, both linguistically (e.g., address terms) and physically (e.g., bodily contact and kissing). Regarding address terms, unlike Western couples who openly express affection by calling each other "honey," "sweetie," and so on, Japanese couples typically call each other either by the first name, sometimes with following suffixes such as -san, by the second person pronoun anata typically used by elderly wives, or by nicknames used by relatively young couples (the last case is more affectionate than the others). If the couples have children, address terms from their children's point of view, such as otoosan/papa ('father') and okaasan/mama ('mother'), can be used. Sometimes address terms can be completely missing, where oi (used by men) or nee (used by women), both interjections meaning 'hey/look,' is used to draw the partner's attention. The above system of the usage of address terms implies that Japanese couples do not express affection much in a conventionalized way, and that they tend to play the social role of father or mother in the family, rather than individual man and woman, once they have children. They might have mixed feelings toward Western couples' affectionate addressing that focuses on a male-female relationship tied by the romantic kind of love: on one hand, they, especially women, may romanticize such a relationship in which they are treated as a woman even after they have children; and on the other hand, they may think such a relationship is too romantic and uncomfortable to them.

Among the three speech participants in Example 2, $\mathrm{K}$ and $\mathrm{S}$ are married to Japanese husbands, while $\mathrm{N}$ is not married but has an American boyfriend. $\mathrm{K}$ also has two small children (three and one years of age) who are present at this setting, occasionally making noises and producing unrecognizable vocalizations during the adults' conversation. S does not have children. 
(2)

((GIRLFRIENDS-1))

$<\mathrm{T}=00: 59: 37.80>$

$1 \mathrm{~K} ; \quad . . n e$,

FP

'Look,'

2

$<$ QUOTE $><$ F $>$ 'beibii $</ \mathrm{F}>$,
baby

3

tte yobaretara yappari,

QT call:PASS:COND assumingly

4

.. $<$ QUOTE $>$ hanii, honey

tte yobundak ke?

QT call Q

'Is it true that when you're called "baby," you call him back "honey?"

$6 \quad \mathrm{~N} ; \quad . . @ @ y o-[(\mathrm{H}) @(\mathrm{H})]$

$7 \quad \mathrm{~S} ; \quad$ [daarin]?.

'(or) "darling?"'

$8 \quad \mathrm{~K} ; \quad=a<\mathrm{F}>$ 'daarin $\quad d a</ \mathrm{F}>$.

oh darling COP

'Oh, it's "darling."”

$9 \quad \mathrm{~N} ;=$ =yoba-nai @yoba-nai@@@[@@][2(H)] call-NEG call-NEG

'I don't call (him so).'

$10 \quad \mathrm{~K}$;

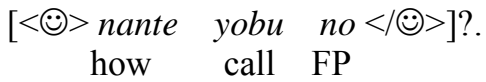

'How do you call (him)?'

$11 \quad \mathrm{~S} ;$

'How do you call (him)?'

$$
\left[{ }_{2}<\odot>\text { nante }\right] \text { yobu no }</ \odot>\text { ? }
$$

how call FP

$12 \mathrm{~N} ; \quad . .<>>$ namae de yondari toka $</$ (;) $>$, name by call or

'I call him by name, or,'

13

.. $<\odot>$ > $>$ [tamani demo $</(\cdot)>$, sometimes but

'But sometimes,'

$14 \quad \mathrm{~K}$;

$\left[<\mathrm{LO}>{ }^{\circ} \mathrm{e}:^{\circ}</\right.$ LO $>$ ]?. ((CHILD'S SLURPING))

'Uh?’

uh 
$15 \mathrm{~N} ; \quad$.. watashi $\left[{ }_{2} \mathrm{mo}\right]$,

I too

$16 \quad \mathrm{~K} ; \quad\left[2^{\circ}\right.$ tamani $\left.^{\circ}\right]$ ? $(($ CHILD'S VOCALIZATION))

'Sometimes?' sometimes

17 N; ..<QUOTE> beibii [3.toka@yonjau@@@@@@@] [5 $(\mathrm{H})]$

baby QT call

'I also call (my boyfriend) "baby."”

$18 \quad \mathrm{~K}$;

$$
\begin{array}{r}
\text { [3@a } @ \text { obeibii] [4@/ne:]. } \\
\text { oh baby FP }
\end{array}
$$

'Oh, you call him "baby."”

19 S;

$$
\text { [4@@] }
$$

20

[5@beibii] [6@/ne: @] [7@(H)]

$$
\text { baby FP }
$$

'You call him "baby".'

$21 \quad \mathrm{~N}$;

[6@@@@@] [7@] [8@@@]

[9(H)@@@] [10 (H)]

$22 \quad \mathrm{~K}$;

$[7 \#:]$,

23

[8 yondemiyou $] \quad\left[{ }_{9} k a<-;\right)>$ kondo: $</ \odot>$ ]@

'Shall we call (our husbands "baby") next time?'

$$
\text { try.to.call Q next.time }
$$

$24 \quad$ S;

[8 iyamo:],

HESIT

'Um,'

25

'Yeah,'

[9 $u: n]$,

yeah

26

[10 yattemiyou] [11 $k a<<>>/ n a:</(\cdot)>$ ].

$$
\text { try.to.do Q FP }
$$

'I wonder if I should try it.'

$27 \quad \mathrm{~K}$;

$$
\text { [11 } u: n] \text {. }
$$$$
\text { yeah }
$$

'Yeah.'

$28 \quad \mathrm{~N}$;

$$
\begin{array}{cl}
{\left[{ }_{11}<\odot\right)>\text { un }} & \text { yat }-</ \odot>] \\
\text { yeah } & \text { do }
\end{array}
$$

$$
\begin{aligned}
& \text {.. konban jaa }<-;>\text { dannasan }\left[{ }_{12} \text { kaettekitara }</ \odot\right)>\text {, } \\
& \text { this.evening then husband come.home } \\
& \text { 'Yeah, then, when your husbands come home this evening, }
\end{aligned}
$$


$30 \quad \mathrm{~K}$;

$\left[{ }_{12}<\right.$ @) $>$ konban $\left.</ \odot>@ @ @\right][13 @]$

'This evening,' this.evening

$31 \quad \mathrm{~N} ; \quad[13 @(\mathrm{H})]$

$32 \mathrm{~S} ; \quad\left[{ }_{13}<\mathrm{VOX}><\mathrm{HI}>{ }^{\circ}\right.$ hai $] /$ beibii: ${ }^{\circ}</ \mathrm{HI}></ \mathrm{VOX}>$ ?.

، "Hi, baby."”

hi baby

$33 \quad \mathrm{~N} ; \quad[14<\mathrm{VOX}>/$ beibii: </VOX>] [15@@@@@]

، "Baby.", baby

34 K; [14@@@] [15@@@ ((CHILD’S VOCALIZATION))

$35 \mathrm{~N} ; \quad<\mathrm{VOX}><\mathrm{LO}>$ nan $d a \quad[16$ omae $</ \mathrm{LO}></ \mathrm{VOX}>$, what COP you

36

toka@iwarechau]@@@@(H)] [17@@@]

QT say:PASS

'He would respond, "What's (wrong with) you?"

37 K; [16@\#\#@\#\#\#nda @yone@@@

38

$\left[{ }_{17}<\mathrm{VOX}><(\cdot)><\mathrm{MRC}><\mathrm{F}>\right.$ un 'nan $\left.d a\right]$ debu $</ \mathrm{F}></ \mathrm{MRC}></ \odot></ \mathrm{VOX}>$ ?, yeah what COP fatso

$<>>$ toka $</(-)>$ [18@iwarechaun @da @yone@>].

$$
\text { QT say:PASS COP FP }
$$

'He would respond, "Yeah, what is it, fatso?"'

40 N; [18@@@@@] [19@(H)@@@] [20 (H)@@@]

41 S; [18@@@@@] [19@@@]

$42 \mathrm{~K} ; \quad\left[{ }_{19} @\right.$ ho:ntoni $<-;>$ zettai $\quad$ sou $\left.</(-)>\right]$,

“It would definitely go that way,'

$\left[{ }_{20}<(-)>\right.$ mou $\quad$ mieteru wa $]\left[{ }_{21}\right.$ watashi $\left.</(;)>\right]$.

'I can tell.' already see FP I

$44 \quad$ S;

[21@@]

$45 \quad \mathrm{~N} ; @ @(\mathrm{SNIFF}) @(\mathrm{SNIFF})[22 @(\mathrm{SNIFF})]((\mathrm{CHILD}$ 'S VOCALIZATION))

$46 \quad \mathrm{~S} ;$

$[22<$;) $>$ uun $]$ de $[23$ ki-nai $</ \odot>>$,

no can-NEG

'No, I can't.' 
$\mathrm{K} ; \quad\left[{ }_{23}<\mathrm{VOX}><\odot<><\mathrm{F}><\mathrm{LO}>/\right.$ de ${ }^{~}$ bii: $</$ LO $\left.></ \mathrm{F}></ \odot><</ \mathrm{VOX}>\right]$ ?, daby

48

$<$;) toka itte $</ \odot>$ [24@@] [25@]

QT say

'(He might even call me,) "daby.”

'That's right.'

$50 \quad \mathrm{~N} ;$

$[25<->$ debii $</ @>][26 @ @ @ @][27 @ @(H)]$

'"Daby".' daby

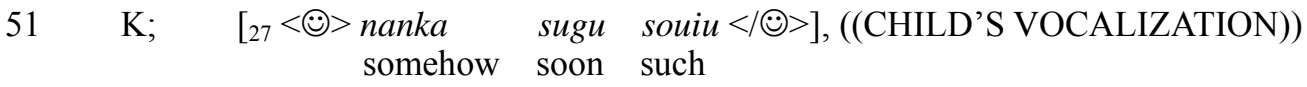

$52 \quad \mathrm{~N} ; \quad[28 @ @]$

$53 \mathrm{~K} ; \quad[28<\odot>$ nanka $]$ are ni $[29$ nacchaunda yone: $</ \odot>]$, somehow that to become FP
$54 \mathrm{~N}$;
[29(H)@@][30@(H)]

$55 \quad \mathrm{~K} ;$
$\left[{ }_{30}<-;>\right.$ wagaya $\quad w a</ \odot>$ ]. ((CHILD’S VOCALIZATION) $)$ our.house TOP
'It always turns that way in our family.'

In lines 1-5, curious about the American way of addressing between a couple, $\mathrm{K}$ asks $\mathrm{N}$ if she calls her American boyfriend "honey," to which $\mathrm{S}$ joins in line 7 by adding an alternative address term "darling," based on her knowledge about the American address system. $\mathrm{N}$ denies either address terms while laughing with embarrassment in lines 6 and $9 . \mathrm{K}$ and $\mathrm{S}$ further ask exactly the same question of how $\mathrm{N}$ addresses her boyfriend, in lines 10 and 11, respectively. $\mathrm{N}$, who first denied with laughter calling her boyfriend either by "honey" or "darling" in line 9, and said that instead she calls him by name in line 12 , now confesses over lines 13,15, and 17, that she sometimes calls him "baby." Meanwhile, $\mathrm{K}$ in particular shows strong interest in this subject, which is manifested by her backchannels in lines 14 and 16, both uttered in a small voice (and lowered pitch in line 14) as if she is ready to hear a secret that should be kept just between them. When K and S find out that $\mathrm{N}$ sometimes calls her American boyfriend "baby," they get thrilled and each repeats the word "baby" with laughter in lines 18 and 20.

$\mathrm{K}$ playfully proposes in line 23 that $\mathrm{K}$ and $\mathrm{S}$ try calling their Japanese husbands "baby" next time, which is supported by $\mathrm{S}$ in line 26 . Here $\mathrm{K}$ and $\mathrm{S}$ start to imagine a hypothetical situation which may not happen in their real life, and thus, this moment marks the beginning of play framing. The contextual shift to a play frame is reinforced when $\mathrm{N}$ gives a concrete suggestion to try it that night, saying konban jaa 
dannasan kaettekitara, ('then, when your husbands come home this evening') in line 29. This invites other speech participants to develop the fantasy world. S takes the opportunity in line 32 and plays a role of a Japanese woman who imitates an American woman to call her husband or boyfriend "baby." S's such playful stance is meta-communicatively indexed by the linguistic style shift. Interestingly, S changes not only the address term "baby" but also the entire phrase in line 32 including "Hi" to English, dedicating herself to dramatization of this role. In addition, when saying "Hi, baby," $\mathrm{S}$ exaggerates prosodic features of a woman's speech style; the rising intonation at the end of "hi," the lengthened and rising intonation on the last syllable of "baby," and the entire phrase in high pitch and small voice are all feminine speech style.

In line 33, $\mathrm{N}$ expresses her parallel play stance to play along with $\mathrm{S}$ with the same female role $\mathrm{S}$ has played, repeating the address term "baby." This verbal stylistic resonance is accompanied by prosodic stylistic resonance, with lengthened and rising intonation uttered in recognizable change-of-voice quality. Using the pragmatic inferences and ideology of Japanese married couples' relationships, $\mathrm{N}$ then proceeds to play a complementary role to that female's role - that is, the role of a husband, who unromantically responds nan da omae ('what's wrong with you?') in line 35, against his wife's aspiration to be addressed back in an affectionate manner. This is the first instance of complementary stylistic resonance in this example. Both verbal form and prosody mark the enacted husband's speech style. Verbally, the use of the plain form of copula $d a$ is masculine, and the second person pronoun omae is a masculine, abrupt, and authoritative address term a husband uses to address his wife. Prosodically, this utterance is produced at the lowered pitch level to portray a male's speech.

This husband's figure that $\mathrm{N}$ has enacted is taken up in K's speech un nan da debu ('yeah, what is it, fatso?') in line 38 and subsequently $\mathrm{N}$ and $\mathrm{S}$ burst into laughter in lines 40 and 41 . The style in this husband's imagined speech shows syntactic resonance in its structure of nan da ('what is it?') followed by an address term, in which the derogative address term debu ('fatso') replaces the previously used address term omae (second person pronoun). The word debu ('fatso') might sound abusive, but it is used here not to hurt someone's feelings, but to show intimacy through teasing. By using debu to refer to herself (she often remarks about herself as fat after giving birth to two children, although actually she is not), $\mathrm{K}$ personalizes this imagined situation that was originally performed by $\mathrm{S}$ and $\mathrm{N}$ as a generalized situation without specifying who the wife and husband are. This speech is uttered in a loud voice, which indexes a man's speech, prosodically in resonance with the masculine lowered pitch level in line 35 , as opposed to the small voice that characterized a woman's speech in line 32 . The marcato prosody also aids in portraying the personality of K's husband, who seems to be enjoying teasing $\mathrm{K}$ in this imagined situation. The husband's role play by $\mathrm{N}$ in line 35 and by $\mathrm{K}$ in line 38 are therefore in pragmatic resonance; they both depict a husband who is perplexed by his wife's sudden change of behavior to call him "baby" 
to express affection, and as a result, does not align to her in a romantic way but replies based on their usual "unromantic" relationship - although intimacy is maintained through teasing. K metalinguistically comments in lines 42 and 43 that she and her husband would end up with this sort of unromantic exchange, saying with a smile hontoni zettai sou, mou mieteru wa watashi ('I can tell it would definitely go that way') and S also expresses by smiling and saying uun deki-nai ('No, I can't') in line 46 that it is impossible for her and her husband to call each other affectionately.

The play finally comes to a climax when $\mathrm{K}$ continues to play the role of her husband in this imagined situation in line 47; this time she spontaneously invents the address term debii coined by combining "de" from debu ("fatso') and "bii" from beibii ('baby'). Prosody that co-occurs debii ('fat baby') resonates the one on beibii ('baby') in lines 32 and 33 with lengthening and rising intonation, but this time with loud voice and the lowered pitch level to show a male's speech style. As opposed to beibii ('baby'), debii ('fat baby') is supposed to be K's husband's speech who teases K by imitating the intonation pattern of 'baby.' $\mathrm{S}$ again aligns to $\mathrm{K}$ in line 49 with laughter in that it would be the case for her husband as well. N's repetition of the humorous key debii with laugher in line 50 is simply regarded as what Tannen ([1989] 2007) calls "savoring" - that is, a kind of repetition that functions to show appreciation of the co-participant's humor. After the role play in this frame ends, $\mathrm{K}$ meta-linguistically comments again, over lines 51,53, and 55, that it always turns that way in her family, meaning between her and her husband. It is interesting that she uses the word wagaya ('our family') here to describe the dynamics of the couple, implying Japanese ideology that puts the family values before the couple as man and woman.

Example 2 is thus another illustration of speech style shift within a play frame. The play frame begins when the speech participants start to humorously talk about the unrealistic situation in which they would try to call their husband "baby." Their playful stances are indexed by paralinguistic devices of laughter and smiling voice quality. The play is intensified over the passage in which the speech participants collaboratively play the roles of the imagined personae of a wife and her husband, which is marked by the shifts in their speech styles. It is first initiated by $\mathrm{S}$, who plays the role of a wife with a generalized identity. The same wife's figure is performed again by $\mathrm{N}$, who also introduces a husband's figure. The significant elements in their play are that (1) the two complementary social roles of a wife and a husband are dynamically enacted, and (2) those social roles' typical speech styles are effectively delineated but exaggerated, probably in order to make them evident so that other speech participants can easily recognize them, as well as to enhance the humorous effects. These points are evidenced by the fact that the speech participants succeeded in inferring that play is going on in the current context (as supported by the abundant occurrence of laughter and laughing/smiling voice quality) and what characters are being enacted. Such successful conversational inferences aided by language ideological understandings of 
male and female speech styles enabled them to properly act out complementary social roles with exaggerated speech styles that show stylistic resonance to each other.

\subsection{Example 3: Male and female; the dubbing register}

The last example is drawn from a mixed-sex conversation between three males and two females whose age ranges from late twenties to early thirties. The speakers are labeled as $\mathrm{M}$ or $\mathrm{F}$ to show their gender followed by the number 1, 2, or 3 in the order of the first appearance in the passage. The three males are close friends and active participants in the conversation. The interlocutors are talking in a relaxed mood, sitting at a dinner table in an informal Japanese restaurant in Tokyo.

This example shows more complexity than the other two as to the stance object - i.e., the entity to which the speech participants take stances. The stance object in this example is a double entity: one is Eric, whose anecdote is being recounted by M1, and the other is the speech style of English-Japanese translation, which M1 employs to report an American female professor's response to Eric. In other words, the speech participants play with the speech style, while simultaneously playing on both Eric's behavior and the speech style of the register of spoken translation of foreign TV programs. Register is "a linguistic repertoire that is associated, culture internally, with particular social practices and with persons who engage in such practices" (Agha 2001: 212). In the Japanese context, the spoken translation of foreign TV programs constitutes one such linguistic repertoire of socially salient registers such as "baby talk" (Ferguson 1977) and "sports announcer talk" (Ferguson 1983) in the American context. The translation register is ideologized as a systematic organization, ideologically distributed in the society, and recognized as such by the social actors in the following example.

((DRINKS-1))

$<\mathrm{T}=00: 15: 38.60>$

$1 \quad \mathrm{M} 1$; $\quad$ (2.8) nanka tanjoobi ga $\begin{array}{cc}\text { ne:, } \\ \text { somehow birthday NOM }\end{array}$

'Well, (his) birthday is,'

2 M2; ...namae?

name

'What's (his) name?'

$3 \mathrm{M} 1 ;=$ ano,

'Um

4

... Erikku no yatsu.

Eric of fellow

'That guy, Eric.' 
(1.5) juu:ichigatsu no nan-nichi ka dattanda yo. November of some-date or COP:PST FP '(His birthday) was someday in November.'

6

F1; .. u:n.

unh-unh

'Unh-unh.'

$7 \quad \mathrm{M} 1 ; \quad . . \mathrm{de}$,

and

'And,'

8

zutto ne,
for.a.long.time $\mathrm{FP}$
'for a long time,

9

... minna ni ne, everyone to FP

10

$<$ QUOTE $>$ kyou hima? today free

11

toka kiiten no.

QT ask FP

'(He) was asking everyone, "Are you free today?" or something like that.'

12

.. ${ }^{\circ}$ kawaii no ${ }^{\circ}$. cute FP

'(He) was cute (to do that).'

$13 \quad \# ; \quad(\mathrm{Hx})$

$14 \mathrm{M} 1 ;$... sensei-gata ni mo kiiten da mon. teacher-PL:POL to too ask COP FP

'Because (he) was also asking (his) teachers.'

151M3; [@@@@@]

16 F1; [@e:@@]

INT

'No way!'

$17 \mathrm{M} 1 ;$ sou,

yes

'It's true,'

$18 \mathrm{~F} 1 ; \quad<\mathrm{e}>\mathrm{sensei}$ made: $</ \odot>$ ? . @

'Even to the teachers?'

$19 \mathrm{M}$; sou,

yes

'That's right,' 
20

.. demo: but 'but,'

21 $\begin{array}{llll}\text { nanka }<\text { QUOTE }>\text { watashi wa toshi o tori-sugita } & \text { kara, } \\ \text { somehow } & \text { I TOP age ACC take-too.much:PST } & \text { because }\end{array}$

'(His offers) were all turned down, like, "I can't drink with you because I aged too much."”

$24 \quad$ M3;

'What a poor guy!'

[

29 M3; [5 omae isshoni] nonde-yare [6 yo omae:]. you together drink-BEN :IMP FP you

'You should (be nice and) drink together (with him).'

$30 \quad$ M2;

$$
\left[{ }_{6}<\odot>\text { ii- } \quad \text { ii } \quad \text { na: }</ \odot>\right] \text {. }
$$

'(That was) nice.'

$$
\text { nice nice FP }
$$

'Your translation was very literal and nice.'

$32 \quad \mathrm{~F} 1$;

$33 \mathrm{M} 3 ; \quad . . n a n k a \quad$ amerika $\left[{ }_{8}\right.$ no $]$, somehow America of 'Something like American,'

$34 \quad$ M2;

$$
\begin{gathered}
{[8<\odot>\text { un }</ \odot>],} \\
\text { yeah }
\end{gathered}
$$

'Yeah,'

$35 \mathrm{M} 3$; nanka are $\left[{ }_{9} \#\right.$ da \#yo], somehow that COP FP

'something like that,' 


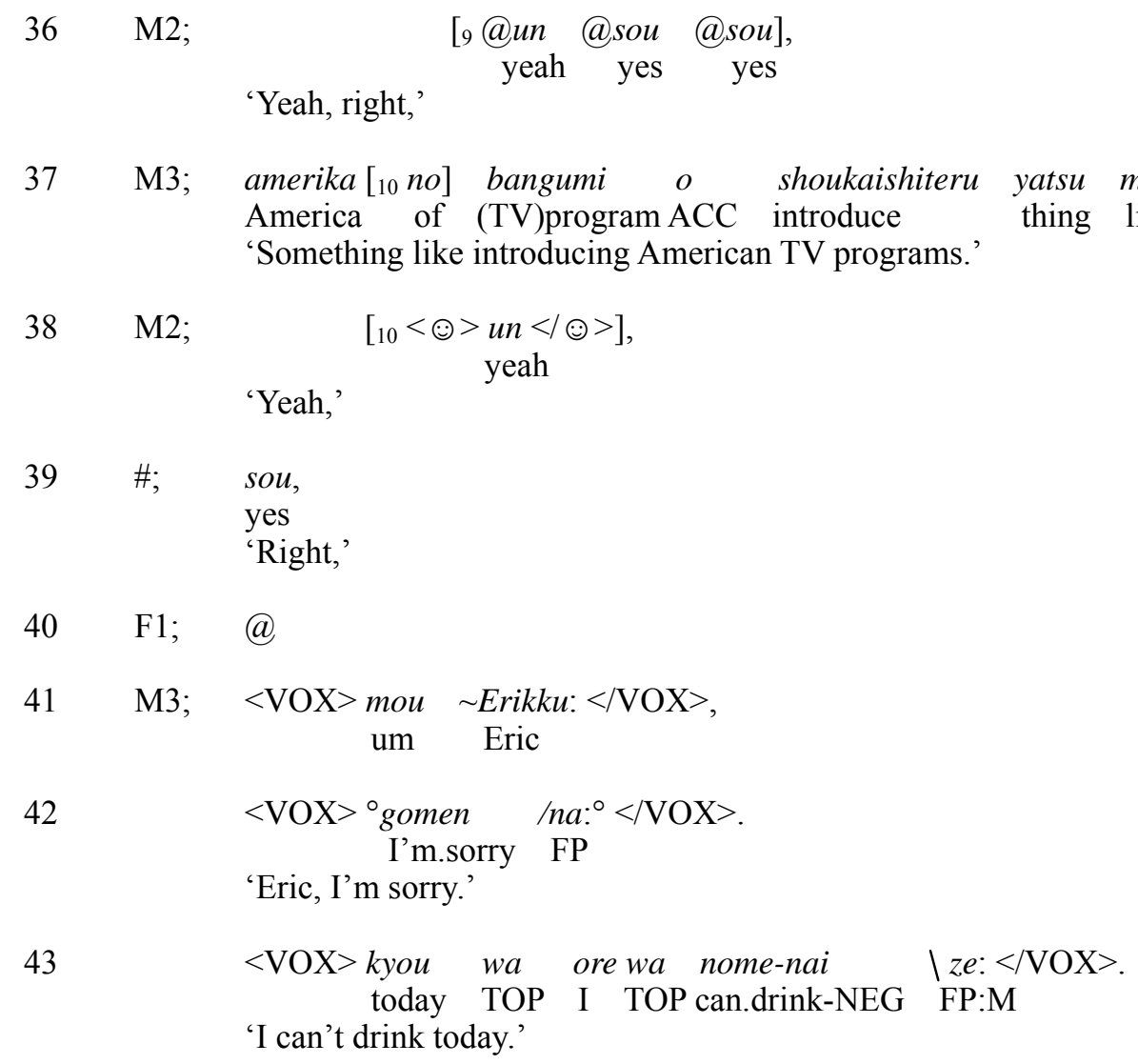
$44 \quad$ M2; $\quad[<\odot>$ un $</ \odot>]$, yeah
'Yeah,'

45.F1; [@@]@@

46 F2; @[2@@]

$47 \quad \mathrm{M} 3 ; \quad\left[{ }_{2}<\mathrm{VOX}>\right.$ chotto kimi $]$ to nomu ni $w a</ \mathrm{VOX}>$, a.little you with drink to TOP

At the beginning of the above excerpt, introducing Eric to his story, M1 starts to recount what happened on Eric's birthday. Eric is an American graduate student who belongs to the same department as M1 does in the United States. In lines 1 and 3-5, M1 tells that Eric's birthday was in November and in lines 7-11 that Eric was asking everyone on his birthday if they were free later that day, wishing to find someone to celebrate his birthday with. Up to this point, M1 is simply telling the facts without any sign of playfulness. The reported speech kyou hima? ('Are you free today?') in line 10 
is a translation of Eric's speech into Japanese, which is not a marked instance of speech style shift since it lacks linguistic or prosodic features of a distinct style.

In line 12, M1 comments on Eric's behavior as kawaii ('cute'), presumably implying "immature," in a small voice which shows iconicity in portraying his childish behavior to ask around to satisfy his desire to celebrate his birthday with someone. M1's empathetic assessment of Eric hints at the upcoming contextual shift to mocking. Then, in line 14, M1 adds more information to Eric's childish behavior, disclosing that he was asking not only his fellow students but also his professors in the department. The final particle mon in sensei-gata ni mo kiiten da mon ('Because he was also asking his teachers') has the reasoning function supporting the previous utterance kawaii no ('He was cute to do that') in line 12. Here, M1's mocking stance toward Eric is exposed. Other participants align their stance along the same line, which is signaled by their laughter. The context has by now shifted to a playful mood to mock Eric, but it is not framed as play yet because neither irrealis modality nor semantic/pragmatic incongruity is involved in the speech. F1 expresses her surprise at Eric's behavior in her utterances $e$ : ('No way!') in line 16 and sensei made:? ('Even to the teachers?') in line 18 , both with the lengthened last syllable that shows her great surprise and high involvement.

Upon confirming what he has said is true in lines 17 and 19, M1 continues to report in line 20 to 23 that everyone whom Eric asked rejected his invitation. As an example, M1 quotes a polite female professor's speech in his Japanese translation watashi wa toshi o tori-sugita kara, anata to isshoni nome-nai wa ('I can't drink with you because I aged too much') in lines 21 and 22, which is considered as the beginning of the play frame due to its dramatization involving irrealis modality and semantic/pragmatic incongruity. This speech sounds unnatural, unrealistic, and funny for the following three reasons. First, the personal pronouns watashi (the first person singular) and anata (the second person singular) occur here against the fact that they usually do not appear in natural speech unless needed for clarification or emphasis. The occurrence of the personal pronouns in this speech can be ascribed to the literal translation of its original English speech that should have those explicit pronouns as the subject and object. Second, this is an overly engendered female speech. This hyper-stylization of female speech is realized through the feminine use of personal pronouns (although watashi and anata can be characterized as polite and formal, it is also feminine at times) and the feminine use of the final particle wa. Wa with a slightly rising intonation as used here is a highly gendered final particle of women, although in reality many Japanese women generally do not use it. Finally, the reason the female professor cannot go out with Eric sounds very unrealistic. One would hardly raise the issue of age to turn down an invitation to go out for drinks, particularly in American culture. It is quite reasonable to interpret that M1 made up the reason, or at least much dramatized what she said, for the sake of play. Provided with these reasons, this M1's 
speech is regarded as play, involving irrealis modality and semantic/pragmatic incongruity.

The play framing thus initiated by M1 is supported by M3 and F1's laughter in lines 24 and 25, respectively. Keeping the stance object of Eric, F2 comments in line 26 that Eric is such a poor guy and M3 says in line 29 that M1 should have had some drinks with him. In contrast, M2 treats the different stance object, namely the speech style M1 has employed in his translation in his meta-linguistic discourse of ii- ii na ('That was nice') in line 30 and sugoi choku-yaku de ii na ima no ('Your translation was very literal and nice') in line 31, in both of which ii ('nice') is supposed to be used sarcastically with the connotation that the translation is "too literal and so terribly bad," and therefore, "funny." The two layers of the stance object thus displayed - namely, Eric and the speech style - are maintained hereafter, although it is only the speech style that is mentioned explicitly. In lines 33, 35, and 37, M3 adds to M2's metalinguistic expression for M1's translation speech style, saying that it sounded like the register translating American TV programs into Japanese. M2's backchannels co-ocurring with smiling voice quality or laughter in lines 34,36 , and 38 demonstrate that M3's interpretation is in accordance with M2. Thus, M2 and M3 collaboratively point out that M1's speech style of spoken translation in lines 21-22 sounded too literal, invoking the register of Japanese dubbing for foreign (specified as "American" in this case) TV programs. As a matter of fact, the Japanese dubbing register in reality may not be that bad, but that is the ideology these speech participants share in their minds.

The play started by M1 in line 21 is intervened as such by the metalinguistic discourse of M2 and M3, and now it resumes in lines 41-43 and 47-48 as M3 enacts an American male persona whose speech carries the same content in the same register as the American female professor reported earlier. Play is now intensified as the degree of non-actuality and incongruity increases. This time, a completely imagined persona is enacted as opposed to the existing female character who actually turned down Eric's invitation. Although it is not clear why M3 performs a male persona, it is conceivable that he transforms the situation into his own imagined experience, while simultaneously retaining the register activated by M1. Linguistically, also, some strategies for hyper-stylization are observed. The American male that M3 enacts here is complementary to the American female in gender, and in this process the Japanese dubbing register is manifested in the male persona's exaggerated speech style that resonates with the female's, building upon Japanese language ideologies of gender introduced through the Japanese translation.

Resonance in hyper-stylization is observed in two respects: (1) the exaggerated gendered speech, and (2) the exaggerated translation register that dubs foreign TV programs. Exaggeration is a typical characteristic of play, but in this case the enactment of American characters seems to be another factor that triggers it: generally, the Japanese have a belief that Americans are cheerful and express 
themselves in lively terms, which could appear to the Japanese themselves as being a little exaggerated. Resonance in the exaggerated gendered speech style is linguistically presented in the uses of the personal pronouns and final particles in the speeches of the male and female personae in the play frame. This type of resonance is pragmatic, and the linguistic features realizing such pragmatic resonance are not identical but complementary. M3 (the second speaker of play) uses conversational inferences to understand M1's (the first speaker of play) speech and pragmatically positions the persona in his imagined playful speech in a complementary way to the persona in M1's speech. The complementary stylistic resonance thus represents and indexes a complementary gender role. The first such complementary stylistic resonance, a type of pragmatic resonance, appears in the use of personal pronouns, ore (the first person singular) in line 43 and kimi (the second person singular) in line 47. These personal pronouns are gender indexes of male speakers in Japanese (although kimi is not exclusively male gendered, but rather distant or authoritative). These pronouns resonate with their female counterparts that appeared in the dramatized professor's reported speech in line 21 to 22; ore (male) resonates with watashi (female, although it can be used by males in the formal context), and kimi (male) resonates with anata (female).

In addition to the personal pronouns, the final particles also serve as the stylistic resources of pragmatic resonance for enacting the complementary male gender role to the female. The final particle ze in line 43 is a hyper-gendered male index (men scarcely use it in natural conversation) that shows complementary stylistic resonance to the hyper feminine final particle $w a$ in line 22. The masculine final particle ze syntactically resonates with the feminine final particle $w a$ as well. Both particles appear following the sentence predicate nome-nai ('cannot drink') with their assertive function to convey the meaning that the subject person cannot drink with Eric; ze in the phrase nome-nai ze, and wa in the phrase nome-nai wa. Besides ze, two other final particles na in gomen na ('I'm sorry') in line 42 and yo (as opposed to its highly feminine version wayo) in toshi o tori-sugita yo ('I aged too much') in line 48 also mark masculinity even though they are sometimes used by women in less feminine contexts.

Stylistic resonance is observed also for the maintenance of the same register within the play frame. First, the occurrence of the explicit personal pronouns ore and kimi in M3's play speech resonates with the occurrence of the personal pronouns watashi and anata in M1's play speech, together evoking the unnatural translation register that dubs foreign TV programs. Second, resonance in the use of the hyper-gendered speech style between M1 and M3's play speeches evokes the translation register that characteristically employs overly gendered language as ideologized in their minds. Third, resonance is seen between the two playful speeches in the use of the stilted speech style that characterizes the dubbed translation register, 
again, as ideologized in the speech participants' minds. This is best represented in the stilted wording in the phrase toshi o tori-sugita ('aged too much'), let alone the fact that it is pragmatically such an unrealistic reason for turning down an invitation. This exact wording first used in M1's play speech in line 21 is repeated by M3 in line 48 in identical resonance. Finally, widened intonation and exaggerated prosody are used in M3's play speech, contributing to activating the translation register. M3's play on register is explicitly marked with lengthening in the intonation unit in lines 41, 42, 43, and 48 , in the widened intonation range toward the end of the intonation unit (rising with gomen na ('I'm sorry') in line 43 and falling with kyou wa ore wa nome-nai ze ('I can't drink today') in line 43), and in soft volume for gomen na ('I'm sorry') in line 43 to overact the male persona who feels sympathetic to Eric when apologizing for having to turn down his invitation. All of the above intonation and prosodic features evoke the dubbed translation register that is ideologically very much exaggerated for the dramatic effects, and thus unnatural compared with ordinary speech, which has much less dramatic intonation and prosody.

As described above, M3's play speech shows complementary resonance with M1's play speech displayed earlier as to gender and register. Such resonance is linguistically marked with culturally identifiable speech styles of males and females and the dubbed translation register. Such stylistically complementary resonance is pragmatically realized through the speech participants' conversational inferences based on their shared cultural ideology. M3, the speaker of the second play speech perceives M1's prior speech as play and positions his speech in the parallel way as play, using the linguistic resources to resonate with M1's speech. The resonance for gender particularly requires advanced pragmatic skills because it is represented through distinct but complementary gender-specific linguistic features - that is, masculine language indexing a male persona as opposed to feminine language indexing a female persona. Gendered language thus performed by M1 and M3 is exaggerated to make it easily recognizable as well as to enhance humorous effects. Play is thus collaboratively framed across the speech participants, and the systematic speech style shifts serve as both the signal of their playful stance and an active resource for constructing the play frame.

\section{Conclusion}

This study has demonstrated that speech style that shifts from the speaker's usual style to the fabricated style of the enacted persona can serve as one of the linguistic strategies to signal play framing. The process of play framing was analyzed interactionally and sequentially, particularly in the context in which speech participants play along, collaboratively uttering play speeches in the co-construction of play frames. 
First, one speaker initiates a play frame by acting a fabricated persona in an imagined situation, and such shifts of voice co-occur with speech style shifts with concurrent linguistic features. The play frame thus signaled by speech style shifts is maintained by other participants, whose parallel play stances are represented by their speech style shifts, newly enacting distinct roles complementary to the previously enacted persona. This mapping relation between the enacted personae's speech styles used across the speech participants represents resonance. In addition to various types of possible resonance that take shape in phonology, morphology, lexical items, syntactic structures, and semantics, this paper proposes a pragmatic type of resonance - more specifically, stylistic resonance that requires the speakers' pragmatic as well as socio-cultural competence. Furthermore, the activity of play framing practiced as such reinforces the speakers' beliefs about the correspondence between the social categories and their stereotypical speech styles, which contributes to the reproduction of culture.

Stylistic resonance in this study was highly pragmatic, and more specifically, complementary. Pragmatic resonance requires speakers' pragmatic skills, namely pragmatic inferences, because it is based not on linguistic forms (phonological, morphological, syntactic, etc.) either in repetition or transformation, but rather on the pragmatic level that is not necessarily apparent in language form. In particular, it is mediated by the speech participants' language ideology of socially salient categories. The second speaker recognizes that other's voice is playfully conveyed by the first speaker through speech style shifts and aligns his or her stance in a parallel way in terms of framing the play, but in the complementary way in terms of social values, both of which are manifested in speech style shifts to systematically organize a contrasting role.

These contrasting social categories are student and professor (Example 1), husband and wife (Example 2), and male and female (Example 3) in this study. It should be noted that each social member's identity in each pair is not fully meaningful in the given contexts unless presented in contrast with the other member of the pair, which requires culturally acquired knowledge of each role's linguistic style. Accordingly, the mapping relationship between these paired members can be considered as a socio-cultural type of resonance, which is a special type of pragmatic resonance.

Thus, the framing process of play mediated by speakers' ideology is highly culture specific. The examples in this paper have demonstrated the importance of Japanese linguistic and cultural resources to the successful manipulation of play framing. For the student and professor pair, the fabricated professor's speech style was linguistically marked by the formal, authoritative, and distant address terms toward the student, the authoritative verb endings, and the special prosody (low, slow, etc.) characteristic of the typical image of a professor who is male, elderly, and authoritative. Its complementary student role was introduced in the resonating speech style shift. It is 
also marked with formality, but with honorifics to convey the polite and deferential student's image that stands opposite in the asymmetrical power structure. In this example, the ideology of the behavioral pattern between professor and student (or rather, teacher and student in general) was also expressed: the student makes a mistake, the professor points it out, and the student apologizes in the end.

The example of the husband and wife pair was elaborated from the more general pair of any man and woman in a relationship. In this pair, the enacted Japanese wife's speech style was featured by the use of the affectionate English address term in rising intonation and high and small voice quality as ideologized in the speakers' minds. Instead of calling her back with an affectionate address term, the fabricated Japanese husband's character in this imagined scenario (played by a woman) responded in Japanese, pointing out the oddness of her behavior. The husband's speech style was linguistically marked by the unromantic but ordinary Japanese address term as well as the masculine form of copula and masculine prosody (loud and low). This example showed not only the ideology of each social role's speech style but also the ideology of the relationship between a Japanese husband and wife, as well as the ideology of a Japanese wife who yearns for the a romantic relationship stereotypical of American couples, as indicated by the affectionate address terms.

In the male and female pair of Example 3, each gender's speech was characterized by highly gendered Japanese personal pronouns and final particles to portray extreme masculinity or femininity. In addition to the language ideology of each gender, this example also demonstrated the ideology of a particular register of dubbed Japanese translation for foreign TV programs, as over-acted and over-gendered, reflecting the Japanese ideology of foreign (specifically American in this case) cultures as more expressive than theirs. This ideology was linguistically manifest in the use of the personal pronouns and hyper-gendered language, and in the stilted and unnatural way of speaking.

All of the above pairs of the complementary social positions were ideologically exaggerated, and their speeches showed hyper-stylization. It is speculated that the speech participants exaggerated the imagined characters' speeches so that their roles as well as play framing could be easily recognized by the other participants. It is also true that such idealized contrasts of the social roles are humorous and thus serve as the useful resources for the purpose of play. These personae may or may not exist in the real world and even the existing personae from whom the fabrication was elaborated can be considerably different from real figures, for the speech participants may or may not know the base characters in person or have correct information about them. Instead, the characters in play are highly ideologized, and the importance is placed not on the individual characters but on the images of their social categories as a group whose social identities are perceived within the network of contrasting social categories in the given culture. Unlike the usual case of speech style studies, the speech 
style in this paper should be regarded not as the self-presentation of the speakers' identities in the situated "serious" context but as the meta-communicative process of the perception and representation of language ideology of fabricated personae in the play context.

Finally, this paper adds a new perspective to the studies of framing through its treatment of framing as not only a contextual but also a socio-cultural phenomenon. Framing is a highly cultural practice in which social values are constantly negotiated and reshaped in local interaction. The notion of framing thus extends to social life, and can reveal how language ideology, as a macro-phenomenon, is actually created in the process of common spontaneous interaction such as play.

\section{References}

Agha, Asif (2001) Register. In Alessandro Duranti (ed.), Key terms in language and culture. Malden, MA: Blackwell, p. 212-215.

Agha, Asif (2007) Language and social relations. Cambridge: Cambridge University Press.

Bakhtin, Mikhail M. (1981) The dialogic imagination: Four essays. Michael Holquist (ed.), C. Emerson and M. Holquist (trans.). Austin: University of Texas Press.

Bateson, Gregory (1972) A theory of play and fantasy. In Steps to an ecology of mind: Collected essays in anthropology, psychiatry, evolution, and epistemology. San Francisco: Chandler Publishing Company, pp. 177-193.

Bauman, Richard (1977) Verbal art as performance. Rowley, MA: Newbury House Publishers.

Bucholtz, Mary (1996) Geek the girl: Language, femininity and female nerds. In J. Ahlers, L. Bilmes, M. Chen, M. Oliver, N. Warner, and S. Werhteim (eds.), Gender and belief systems. Berkeley, CA: Berkeley Women and Language Group, pp. 119-182.

Bucholtz, Mary, and Kira Hall (2005) Identity and interaction: A sociocultural linguistic approach. Discourse Studies 7.4-5: 585-614.

Du Bois, John W. (1999) Activating affinities: Resonance in dialogic syntax. Paper presented at the Linguistics Colloquium, University of California, Santa Barbara.

Du Bois, John W. (2002a) Stance and intersubjectivity in dialogic interaction. Paper presented at the Linguistics Colloquium, University of California, Santa Barbara.

Du Bois, John W. (2002b) Stance and consequence. Paper presented at the American Anthropological Association, New Orleans.

Du Bois, John W. (2003) Stance and consequence in interaction. Paper presented at the Language, Interaction, and Social Organization Colloquium, University of California, Santa Barbara.

Du Bois, John W. (2006) Transcription convention updates. Retrieved from http://www.linguistics.ucsb.edu/projects/transcription/A05updates.pdf. 
Du Bois, John W. (2007) The stance triangle. In Robert Englebretson (ed.), Stancetaking in discourse: Subjectivity, evaluation, interaction. Amsterdam: John Benjamins Publishing Company, pp. 139-182.

Du Bois, J.W., S. Schuetze-Coburn, S. Cumming, and D. Paolino (1993) Outline of discourse transcription. In J.A. Edwards and M.D. Lampert (eds.), Talking data: Transcription and coding in discourse research. Hillsdale, NJ: Erlbaum, pp. 45-89.

Eckert, Penelope (2000) Linguistic variation as social practice. Oxford: Blackwell.

Eckert, Penelope, and John R. Rickford (eds.) (2001) Style and sociolinguistic variation. Cambridge: Cambridge University Press.

Englebretson, Robert (ed.) (2007) Stancetaking in discourse: Subjectivity, evalutaion, interaction. Amsterdam: John Benjamins Publishing Company.

Ervin-Tripp, Susan (1972) On sociolinguistic rules: Alternation and co-occurrence. In J. Gumperz and D. Hymes (eds.), Directions in sociolinguistics: The ethnography of communication. New York: Holt, Rinehart and Winston, pp. 213-250.

Ferguson, Charles A. (1977) Baby talk as a simplified register. In Catherine E. Snow and Charles A. Ferguson (eds.), Talking to children: Language input and acquisition. New York: Cambridge University Press, pp. 209-235.

Ferguson, Charles A. (1983) Sports announcer talk: Syntactic aspects of register variation. Language in Society 12.2: 153-172.

Goffman, Erving (1974) Frame analysis: An essay on the organization of experience. Boston: Northeastern University Press..

Goffman, Erving (1981) Forms of talk. Philadelphia: University of Pennsylvania Press.

Gumperz, John J. (1982) Discourse strategies. Cambridge: Cambridge University Press.

Gumperz, John J. (1989a) Contextualization and understanding. In Alessandro Duranti and Charles Goodwin (eds.), Rethinking context. Cambridge: Cambridge University Press, pp. 229-252.

Gumperz, John J. (1989b) Contextualization cues and metapragmatics: The retrieval of cultural knowledge. In C. Wiltshire, B. Music, and B. Craczyk (eds.), Chicago Linguistic Society 25: Papers from the parasession on language in context. Chicago: University of Chicago Press, pp. 10-35.

Gumperz, John J. (1996) The linguistic and cultural relativity of conversational inference. In John J. Gumperz and Stephen C. Levinson (eds.), Rethinking linguistic relativity. Cambridge: Cambridge University Press, pp. 374-406.

Hunston, Susan, and Geoff Thompson (eds.) (2000) Evaluation in text: Authorial stance and the construction of discourse. Oxford: Oxford University Press.

Irvine, Judith T. (2001) "Style" as distinctiveness: The culture and ideology of linguistic differentiation. In Penelope Eckert and John R. Rickford (eds.), Style and sociolinguistic variation. Cambridge: Cambridge University Press, pp. 21-43.

Labov, William (1966) The social stratification of English in New York City. Washington, D.C.: Center for Applied Linguistics. 
Mendoza-Denton, Norma (1997) Chicana/Mexicana identity and linguistic variation: An ethnographic and sociolinguistic study of gang affiliation in an urban high school. Unpuglished Ph.D. dissertation. Stanford University, Department of Anthropology.

Mendoza-Denton, Norma (2001) Style. In Alessandro Duranti (ed.), Key terms in language and culture. Malden, MA: Blackwell, pp. 235-237.

Rickford, John R., and Penelope Eckert (2001) Introduction. In Penelope Eckert and John R. Rickford (eds.), Style and sociolinguistic variation. Cambridge: Cambridge University Press, pp. 1-18.

Sapir, Edward (1958) Speech as a personality trait. In David Mandelbaum (ed.), Selected writings of Edward Sapir in language, culture, and personality. Berkeley, CA: University of California Press, pp. 533-543.

Schieffelin, Bambi B., Kathryn A. Woolard, and Paul V. Kroskrity (eds.) (1998) Language ideologies: Practice and theory. New York: Oxford University Press.

Sherzer, Joel (1990) Verbal art in San Blas: Kuna culture through its discourse. Cambridge: Cambridge University Press.

Silverstein, Michael (1979) Language structure and linguistic ideology. In Paul R. Clyne, William F. Hanks, and Carol L. Hofbauer (eds.), The elements: A parasession on linguistic units and levels. Chicago: Chicago Linguistic Society, pp. 193-247.

Silverstein, Michael (1992) The uses and utility of ideology: Some reflections. In Paul Kroskrity, Bambi B. Schieffelin, and Kathryn A. Woolard (eds.), Special issue of Pragmatics 2.3: 311-324.

Takanashi, Hiroko (2004) The interactional co-construction of play in Japanese conversation. Unpublished Ph.D. dissertation. University of California at Santa Barbara, Department of Linguistics.

Tannen, Deborah (1984) Conversational style: Analyzing talk among friends. Norwood, NJ: Ablex.

Tannen, Deborah (ed.) (1993) Framing in discourse. New York: Oxford University Press.

Tannen, Deborah ([1989] 2007) Talking the dog: Framing pets as interactional resources in family discourse. In Deborah Tannen, Shari Kendall,and Cynthia Gordon (eds.), Family talk: Discourse and identity in four American families. Oxford: Oxford University Press.

\section{Appendix A: Transcription conventions}

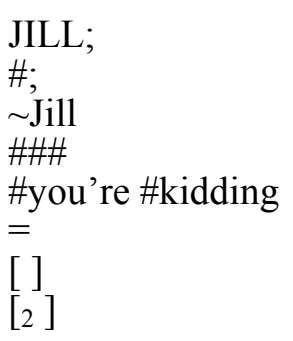

((WORDS))

$((\mathrm{SOURCE}))$ $<\mathrm{T}=00: 42: 35.00>$ speaker label uncertain speaker pseudograph: name change to preserve anonymity one symbol per unintelligible syllable

transcribed words are uncertain no pause between the two speakers' turns overlap (first set): align left square brackets vertically overlap (2nd set): align left brackets, co-indexed with subscript numeral analyst comment on any topic recording source time in seconds from start of recording 


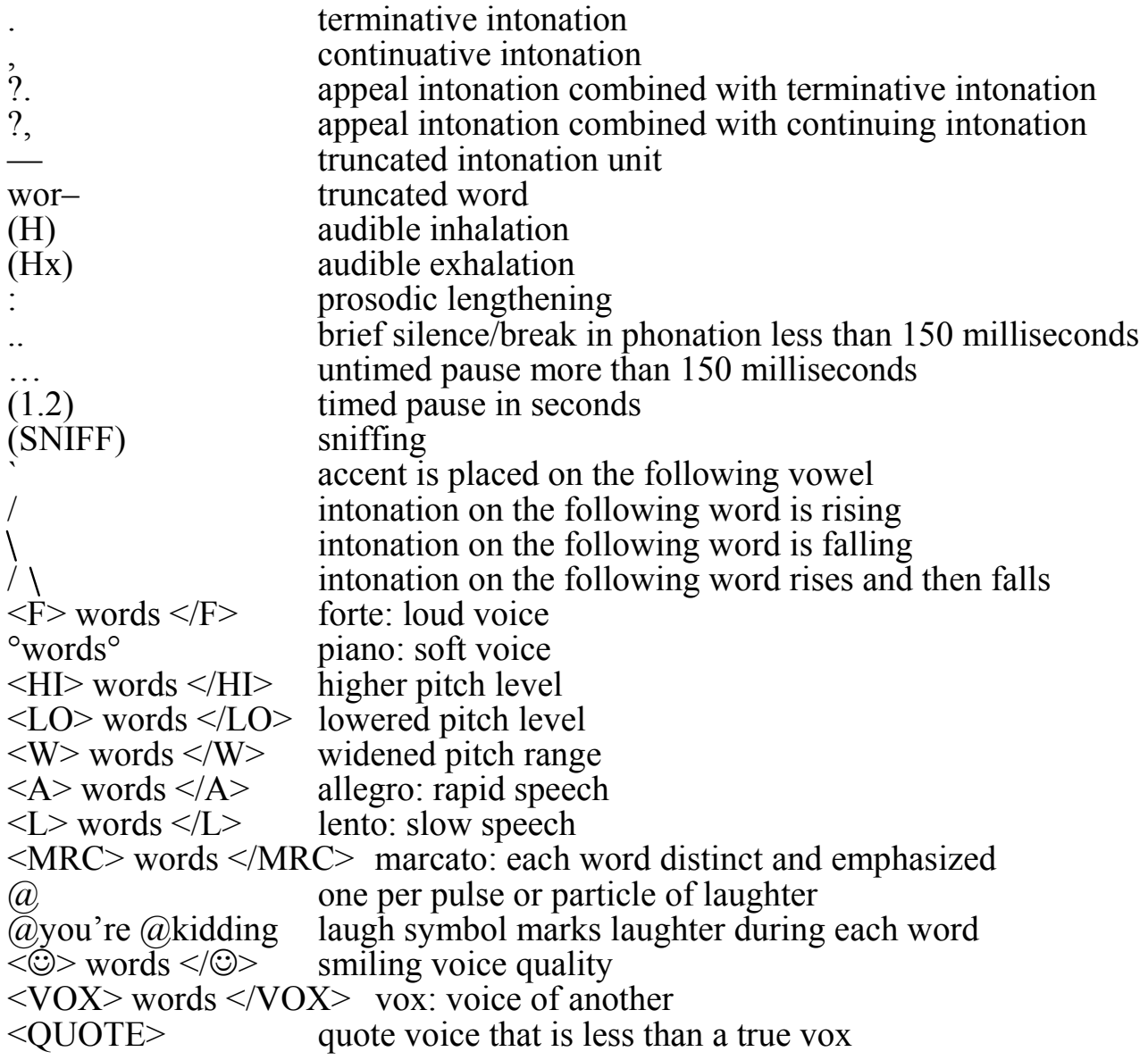

\section{Appendix B: Gloss}

$\begin{array}{ll}\text { ACC: } & \text { accusative } \\ \text { BEN: } & \text { benefactive } \\ \text { COND: } & \text { conditional } \\ \text { COP: } & \text { copula } \\ \text { F: } & \text { female index } \\ \text { FP: } & \text { final particle } \\ \text { HESIT: } & \text { hesitation } \\ \text { IMP: } & \text { imperative } \\ \text { INT: } & \text { interjection } \\ \text { LK: } & \text { linker } \\ \text { M: } & \text { male index } \\ \text { NEG: } & \text { negation } \\ \text { NOM: } & \text { nominative } \\ \text { NOMLIZER: } & \text { nominalizer } \\ \text { PASS: } & \text { passive } \\ \text { PL: } & \text { plural } \\ \text { POL: } & \text { polite form } \\ \text { PST: } & \text { past } \\ \text { Q: } & \text { question particle }\end{array}$


QT: quotative

TOP : topic

HIROKO TAKANASHI is associate professor of linguistics at Japan Women's University. Her research interests include interactional sociolinguistics and linguistic anthropology, and her particular focus is on play, among other metalinguistic interactions.

Address : Department of English, Japan Women's University, 2-8-1 Mejirodai, Bunkyo-ku, Tokyo 112-8681, Japan.

E-mail : takanashi@fc.jwu.ac.jp 